\title{
Fuzzy Soft Generalized Closed Sets in Fuzzy Soft Topological Spaces
}

\author{
Zeba Tarrannum and Anil P Narappanavar* \\ Department of Mathematic, Global Academy of Technology, \\ Bengaluru - 560098, Karnataka, India. \\ *Corresponding author
}

\begin{abstract}
In this paper we introduce fuzzy soft g-closed set, fuzzy soft $\mathrm{g}^{*}$ - closed set and fuzzy soft strongly $\mathrm{g} *$ - closed set and study their relations. Also fuzzy soft g-continuous functions in fuzzy soft topological spaces have been introduced and few of their properties have been studied.
\end{abstract}

Keywords: Fuzzy soft Topology, Fuzzy soft g-closed set, Fuzzy soft $\mathrm{g} *$-closed set, Fuzzy soft strongly $\mathrm{g} *$-closed set and fuzzy soft $\mathrm{g}$-continuous functions.

\section{INTRODUCTION}

The fuzzy set is a generalization of regular set. In a regular set an element is either a member of the set or not .But a fuzzy set has a graphical description. This graphical description is called a membership function valued in the unit interval $[0$, 1].L.A Zadeh [1] initiated the concept of Fuzzy soft set and provided a natural base to handle and improve mathematically the Fuzzy phenomenon found in different areas of knowledge. C.L Chang [2] studied and discussed Fuzzy topological spaces. B.Ahmad and A.Kharral [3] investigated fuzzy soft sets and established Fuzzy soft functions on Fuzzy soft classes. The notion of topological structure of Fuzzy soft sets was introduced by Tanay and Kandemir [4] in 2011 and studied further by Varol and Aygun [5].

The concept of generalized closed sets plays a significant role in topology. There are many research papers which deal with different types of generalized closed sets. In 1970, Levine [6] introduced the concept of generalized closed set in the topological spaces (briefly g-closed).g*-closed sets were introduced and studied by Veerakumar [7] for general topology. Recently Parimelazhagan and Subramonia Pillai introduced strongly $\mathrm{g} *$-closed sets in topological space [8]. In 2013 the strongly $\mathrm{g} *$ - closed sets in fuzzy topological spaces was introduced by T.Rajendra Kumar and Anandajothi [9]

Accordingly, the proposed study is to introduce a new class of fuzzy soft closed sets namely fuzzy soft generalized closed set, fuzzy soft $\mathrm{g}^{*}$-closed set, fuzzy soft strongly $\mathrm{g}^{*}$ - closed sets in fuzzy soft topological space and study their properties. Further we define and investigate few properties of fuzzy soft g-continuous functions in fuzzy soft topological space.

\section{PRELIMINARIES}

Definition $2.1^{[10]}$ : Let $X$ be the initial universe and $E$ be the set of parameters. $I^{x}$ be the set of all fuzzy sets on $X$. Let $A \subseteq E$ and $f: A \rightarrow I^{x}$. A pair $(f, A)$ is called fuzzy soft set over X. It is also denoted by $f_{A}$ i.e. for every $a \in A, f(a)=f_{a}: X \rightarrow I$ is a fuzzy set on $\mathrm{X}$.

Definition $2.2^{[11]}$ : Let $\tau$ be a collection of all fuzzy soft sets over a universe $X$ with a fixed set of parameter set $E$ then a triplet $(X, \tau, E)$ is called fuzzy soft topological space [FSTS] if it satisfies the following axioms.

(i) $\tilde{0}_{E}, \tilde{1}_{E} \in \tau$

(ii)Arbitrary union of members of $\tau$ is a member of $\tau$.

(iii) Finite intersection of members of $\tau$ is a member of $\tau$.

Every member of $\tau$ is called fuzzy soft open set i.e. a fuzzy soft set $f_{A} \in \tau$ is called fuzzy soft open set in $\mathrm{X}$ and its complement $1-f_{A}$ is called fuzzy soft closed set.

Definition $2.3^{[5]}$ : The intersection of all fuzzy soft closed super sets of $f_{A}$ is called fuzzy soft closure of $f_{A}$ denoted by, $\operatorname{Fscl}\left(f_{A}\right)$.

$\operatorname{Fscl}\left(f_{A}\right)=\bigcap\left\{h_{D}, h_{D}\right.$ is fuzzy soft closed set and $\left.f_{A} \subseteq h_{D}\right\}$

Definition $2.4^{[5]}$ : The union of all fuzzy soft open subsets of $g_{B}$ is called fuzzy soft interior of $g_{B}$ denoted by $F \operatorname{sint}\left(f_{A}\right)$. Fs $\operatorname{int}\left(g_{B}\right)=\bigcup\left\{h_{D}, h_{D}\right.$ is fuzzy soft open set and $\left.h_{D} \subseteq g_{B}\right\}$

Definition $2.5^{[7]}$ : A Fuzzy soft set $f_{A}$ in Fuzzy soft topological space $(X, \tau, E)$ is called Fuzzy soft semi-open if $f_{A} \leq F s c l F s i n t\left(f_{A}\right)$, Fuzzy soft semi-closed if $F \operatorname{sint} F \operatorname{scl}\left(f_{A}\right) \leq f_{A}$ 
Definition 2.6 $6^{[12]}$ : A Fuzzy soft set $f_{A}$ in Fuzzy soft topological space $(X, \tau, E)$ is called Fuzzy soft pre-open if $f_{A} \leq$ Fsint Fscl $\left(f_{A}\right), \quad$ Fuzzy $\quad$ soft $\quad$ pre-closed if $\operatorname{Fscl} F \operatorname{sint}\left(f_{A}\right) \leq f_{A}$

Definition 2. $7^{[12]}$ : A Fuzzy soft set $f_{A}$ in Fuzzy soft topological space $(X, \tau, E)$ is called Fuzzy soft regular open if $f_{A}=$ Fsint $\operatorname{Fscl}\left(f_{A}\right)$, Fuzzy soft regular-closed if $F s c l F \operatorname{sint}\left(f_{A}\right)=f_{A}$

\section{FUZZY SOFT GENERALIZED CLOSED SETS}

A Fuzzy soft set $f_{A}$ in Fuzzy soft topological space $(X, \tau, E)$ is called Fuzzy soft generalized closed set (in short Fs g-closed) if $\operatorname{Fscl}\left(f_{A}\right) \leq H, \forall f_{A} \leq H$ and $\mathrm{H}$ is Fuzzy soft open in $\mathrm{X}$.

Theorem 3.1: Every fuzzy soft closed set is fuzzy soft generalized closed set in a fuzzy soft topological space $(X, \tau, E)$.

Proof: Let A be a fuzzy soft closed set in $\mathrm{X}$. Let $\mathrm{A} \leq \mathrm{H}$ where $\mathrm{H}$ is fuzzy soft open. Since $\mathrm{A}$ is fuzzy soft closed Fscl (A) = $\mathrm{A} \leq \mathrm{H}$. Thus we have Fscl (A) $\leq \mathrm{H}$ whenever $\mathrm{A} \leq \mathrm{H}$. Therefore, A is fuzzy soft generalized closed set.

The converse of the above theorem need not be true in general which can be seen from the following example.

Let $\tau=\left\{\tilde{0}, \tilde{1},\left(F_{1}, E\right),\left(F_{2}, E\right)\right\},\left(F_{1}, E\right)=\{0.5,0.7\}$, $\left(F_{2}, E\right)=\{0.25,0.2\}$

Let $H=\{0.5,0.7\}, \quad A=\{0.4,0.2\}$

$A$ is fuzzy soft generalized closed set but not fuzzy soft closed set in X... $\square$

Theorem 3.2: For any two fuzzy soft generalized closed sets $\mathrm{A}$ and $\mathrm{B} F s c l(A \vee B)=F s c l(A) \vee F s c l(B)$

Proof: Let A and B be any two fuzzy soft generalized closed sets in FSTS $(X, \tau, E)$

$$
\begin{aligned}
& A \leq A \vee B \Rightarrow F \operatorname{Fsl}(A) \leq F \operatorname{Fcl}(A \vee B) \\
& B \leq A \vee B \Rightarrow F \operatorname{Fsl}(B) \leq F s c l(A \vee B) \\
& F \operatorname{Fsl}(A) \vee F \operatorname{Fbcl}(B) \leq F \operatorname{Fsl}(A \vee B)
\end{aligned}
$$

Also $F s c l(A)$ and $F \operatorname{sbcl}(B)$ are the closed sets.

$\therefore \operatorname{Fscl}(A) \vee \operatorname{Fsbcl}(B)$ is also a closed set.
Again,

$$
A \leq F \operatorname{Fcl}(A) \text { and } B \leq F s c l(B) \Rightarrow A \vee B \leq F s c l(A) \vee F s c l(B)
$$

Thus $\operatorname{Fscl}(A) \vee \operatorname{Fscl}(B)$ is a closed set containing $A \vee B$

$\therefore F \operatorname{Fsl}(A \vee B) \leq F s c l(A) \vee F \operatorname{Fsl}(B)$

Thus $\operatorname{Fscl}(A \vee B)=\operatorname{Fscl}(A) \vee \operatorname{Fscl}(B)$

Theorem 3.3: Union of two fuzzy soft generalized closed sets in $\mathrm{X}$ is a fuzzy soft generalized closed set in $\mathrm{X}$.

Proof: Let A and B be any two fuzzy soft generalized closed sets in $\operatorname{FSTS}(X, \tau, E)$

Let $A \vee B \leq H$ where $\mathrm{H}$ is fuzzy soft open. Since A and $\mathrm{B}$ are fuzzy soft generalized closed sets

$\Rightarrow \operatorname{Fscl}(A) \vee \operatorname{Fscl}(B) \leq H$

But $\operatorname{Fscl}(A) \vee F s c l(B)=\operatorname{Fscl}(A \vee B)$

$\therefore \quad \operatorname{Fscl}(A \vee B) \leq H$

Hence $A \vee B$ is a fuzzy soft generalized closed set.

Theorem 3.4: If a subset $A$ of $X$ is a fuzzy soft generalized closed set in $\mathrm{X}$ and $\mathrm{A} \leq B \leq \operatorname{Fscl}(A)$, then $\mathrm{B}$ is fuzzy soft generalized closed set in $X$.

Proof: Let A be a fuzzy soft generalized closed set such that $\mathrm{A} \leq B \leq \operatorname{Fscl}(A)$.

Let $\mathrm{H}$ be a fuzzy soft open set in $\mathrm{X}$ such that $B \leq H$. Since $\mathrm{A}$ is fuzzy soft generalized closed set we have $\operatorname{Fscl}(A) \leq H$ i.e $\operatorname{Fscl}(B) \leq H, \mathrm{H}$ is fuzzy soft open in $\mathrm{X}$.

Therefore B is fuzzy soft generalized closed set in X.

\section{FUZZY SOFT $\mathrm{g} *$-CLOSED SET}

A Fuzzy soft set $f_{A}$ in Fuzzy soft topological space $(X, \tau, E)$ is called Fuzzy soft $\mathrm{g}^{*}$-closed set (in short Fs $\mathrm{g}^{*}$ closed) if $F s c l\left(f_{A}\right) \leq H, \forall f_{A} \leq H$ and $\mathrm{H}$ is Fuzzy soft generalized open set in $\mathrm{X}$.

Theorem 4.1: Every fuzzy soft closed set is fuzzy soft $\mathrm{g} *$ closed set in a fuzzy soft topological space $(X, \tau, E)$.

Proof: Let A be a fuzzy soft closed set in $\mathrm{X}$. Let $\mathrm{A} \leq \mathrm{H}$ where $\mathrm{H}$ is fuzzy soft g-open. Since $\mathrm{A}$ is fuzzy soft closed Fscl $(\mathrm{A})=$ $\mathrm{A} \leq \mathrm{H}$. Thus we have Fscl $(\mathrm{A}) \leq \mathrm{H}$ whenever $\mathrm{A} \leq \mathrm{H}$, therefore A is fuzzy soft $\mathrm{g}^{*}$ closed set.

Theorem 4.2: Every fuzzy soft $\mathrm{g}^{*}$ - closed set is fuzzy soft $\mathrm{g}$ closed set in a fuzzy soft topological space $(X, \tau, E)$.

Proof: Let A be a fuzzy soft $\mathrm{g}^{*}$ - closed set in $\mathrm{X}$. Let $\mathrm{A} \leq \mathrm{H}$ where $\mathrm{H}$ is fuzzy soft $\mathrm{g}$-open. Since $\mathrm{A}$ is fuzzy soft $\mathrm{g} *$ - closed Fscl $(\mathrm{A}) \leq \mathrm{H}$. Thus we have Fscl $(\mathrm{A}) \leq \mathrm{H}$ whenever $\mathrm{A} \leq \mathrm{H}$. 
Since every open set is g-open, therefore A is fuzzy soft gclosed set.

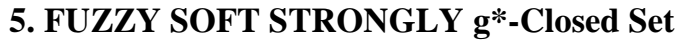

A Fuzzy soft set $f_{A}$ in Fuzzy soft topological space $(X, \tau, E)$ is called Fuzzy soft strongly $\mathrm{g} *$-closed set if Fscl Fs $\operatorname{int}\left(f_{A}\right) \leq H, \forall f_{A} \leq H$ and $\mathrm{H}$ is Fuzzy soft generalized open set in $\mathrm{X}$.

Theorem 5.1: Every fuzzy soft closed set is a fuzzy soft strongly $\mathrm{g} *$ - closed set in a fuzzy soft topological space $(X, \tau, E)$.

Proof: Let A be a fuzzy soft closed set in X. Let $\mathrm{H}$ be fuzzy soft generalized open set in $X$ such that $A \leq H$. Since $A$ is fuzzy soft closed, Fscl (A) =A. Fscl (A) $\leq$ H. Now, Fscl Fsint (A) $\leq$ Fscl $(\mathrm{A}) \leq \mathrm{H}$. Hence $\mathrm{A}$ is fuzzy soft strongly $\mathrm{g} *_{-}$ closed set in $\mathrm{X}$.

The converse of the above theorem need not be true in general which can be seen from the following example.

Let $\tau=\left\{\tilde{0}, \tilde{1},\left(F_{1}, E\right),\left(F_{2}, E\right)\right\}$

Where $\quad\left(F_{1}, E\right)=\{0.5,0.8\} \quad, \quad\left(F_{2}, E\right)=\{0.25,0.2\}$

$\mathrm{H}=\{0.5,0.8\}, \mathrm{A}=\{0.45,0.3\}$. Then $\mathrm{A}$ is fuzzy soft strongly $\mathrm{g}^{*}$ - closed but it is not fuzzy soft closed set in $(X, \tau, E)$.

Theorem 5.2: Every fuzzy soft generalized closed set is fuzzy soft strongly $\mathrm{g}^{*}$ - closed set in a fuzzy soft topological space $(X, \tau, E)$.

Proof: Let A be a fuzzy soft generalized closed set in X. Let $\mathrm{H}$ be fuzzy soft generalized open set in $X$ such that $A \leq H$. Since A is fuzzy soft generalized closed set, Fscl (A) $\leq \mathrm{H}$.

Now, Fscl Fsint (A) $\leq$ Fscl (A) $\leq$ H. Hence A is fuzzy soft strongly $\mathrm{g} *$ - closed set in $\mathrm{X}$.

The converse of the above theorem need not be true in general which can be seen from the following example.

Let $\tau=\left\{0,1,\left(\mathrm{~F}_{1}, \mathrm{E}\right),\left(\mathrm{F}_{2}, \mathrm{E}\right)\right\}$

Where $\left(\mathrm{F}_{1}, \mathrm{E}\right)=\{0.5,0.8\},\left(\mathrm{F}_{2}, \mathrm{E}\right)=\{0.25,0.2\}$

$\mathrm{H}=\{0.5,0.8\} \mathrm{A}=\{0.45,0.3\}$. Then $\mathrm{A}$ is fuzzy strongly $\mathrm{g} *_{-}$ closed but it is not fuzzy soft generalized set.

Theorem 5.3: Every fuzzy soft $g^{*}$-closed set is a fuzzy soft strongly $\mathrm{g} *$-closed set in $\mathrm{X}$.

Proof: Suppose that A is fuzzy soft $\mathrm{g}^{*}$-closed set in $\mathrm{X}$. Let $\mathrm{H}$ be a fuzzy soft generalized open set in $X$ such that $A \leq H$. Then Fscl $(\mathrm{A}) \leq \mathrm{H}$, since $\mathrm{A}$ is fuzzy soft $\mathrm{g}^{*}$ - closed set.

Now, Fscl Fsint $(\mathrm{A}) \leq$ Fscl $(\mathrm{A}) \leq \mathrm{H}$. Hence A is fuzzy soft strongly $\mathrm{g} *$ - closed set in $\mathrm{X}$.

Theorem 5.4: If $A$ is both open and strongly $g *$-closed in $X$ then it is both regular open and regular closed in X.

Proof: Suppose A is a fuzzy soft open in X.
$A=F \operatorname{sint}(A)=$ Fsint Fscl $(A)$ since $A$ is closed

Thus $\mathrm{A}$ is regular open.

Again A is open in X, Fscl Fsint $(\mathrm{A})=\mathrm{Fscl}(\mathrm{A})$

As $\mathrm{A}$ is closed, Fscl Fsint $(\mathrm{A})=\mathrm{A}$

Thus A is regular closed.

Theorem 5.5: In FSTS every fuzzy soft pre-closed set is fuzzy soft strongly $\mathrm{g} *$-closed in $\mathrm{X}$.

Proof: Let A be fuzzy soft pre-closed set in $\mathrm{X} \Rightarrow$ Fscl Fsint (A) $\leq \mathrm{A}$

Let $\mathrm{A} \leq \mathrm{H}$ and $\mathrm{H}$ is g-open in $\mathrm{X} \Rightarrow \mathrm{Fscl} F$ sint $(\mathrm{A}) \leq \mathrm{H}$ where $\mathrm{H}$ is g-open in $\mathrm{X}$.

$\Rightarrow \mathrm{A}$ is fuzzy soft strongly $\mathrm{g}^{*}$-closed set in $\mathrm{X}$.

\section{FUZZY SOFT G-CONTINUOUS AND SEMI g-CONTINUOUS FUNCTIONS}

Definition 6.1: A function $f:(X, \tau) \rightarrow\left(Y, \tau^{\prime}\right)$ is said to be fuzzy soft $\mathrm{g}$ - continuous (FSg- continuous) if for every fuzzy soft open $\operatorname{set}(G, E) \in \tau^{\prime}, f^{-1}(G, E)$ is fuzzy soft gopen set in $\tau$.

Theorem 6.2: If $\mathrm{A}$ is a fuzzy soft $\mathrm{g}$-closed set in $\mathrm{X}$ and if $f:(X, \tau) \rightarrow\left(Y, \tau^{\prime}\right)$ continuous and fuzzy soft closed, then $\mathrm{f}(\mathrm{A})$ is fuzzy soft $\mathrm{g}$ - closed in $\mathrm{Y}$.

Proof: If $\mathrm{f}(\mathrm{A}) \leq \mathrm{O}^{\prime}$ where $\mathrm{O}^{\prime}$ is fuzzy soft open in $\mathrm{Y}$, then $\mathrm{A}$ $\leq f^{-1}\left(O^{\prime}\right)$ and hence

Fscl $(\mathrm{A}) \leq f^{-1}\left(O^{\prime}\right)$. Thus $F s c l(A) \leq O^{\prime}$ and $f[F s c l(A)]$ is a closed set. It follows that $\operatorname{Fscl}(f[A]) \leq \operatorname{Fscl}(f[\operatorname{Fscl}(A)])=f[\operatorname{Fscl}(A)] \leq O^{\prime}$.

Then $F s c l(f[A]) \leq O^{\prime}$ and $\mathrm{f}(\mathrm{A})$ is fuzzy soft g-closed.

Definition 6.3: A function $f:(X, \tau) \rightarrow\left(Y, \tau^{\prime}\right)$ is called fuzzy soft semi - continuous if for every fuzzy soft closed set $(G, E) \in \tau^{\prime}, f^{-1}(G, E)$ is fuzzy soft semi-closed set in $\tau$.

Definition 6.4: A function $f:(X, \tau) \rightarrow\left(Y, \tau^{\prime}\right)$ is called fuzzy soft semi $\mathrm{g}$ - continuous if for every fuzzy soft $\mathrm{g}$-closed $\operatorname{set}(G, E) \in \tau^{\prime}, f^{-1}(G, E)$ is fuzzy soft semi-closed set in $\tau$.

Theorem 6.5: Every fuzzy soft semi-g-continuous function is fuzzy soft semi-continuous function.

Proof: Let $\mathrm{f}$ be a function $f:(X, \tau) \rightarrow\left(Y, \tau^{\prime}\right)$. Let $\mathrm{V}$ be a fuzzy soft open set in Y. Since every fuzzy soft open set is fuzzy soft g-open and $\mathrm{f}$ is fuzzy soft semi-g-continuous. Hence $\mathrm{f}$ is fuzzy soft semi-continuous function. 
Converse of the above theorem is not true in general as shown by the following example.

Let $f:(X, \tau) \rightarrow\left(Y, \tau^{\prime}\right)$

$\tau=\left\{\tilde{0}, \tilde{1},\left(F_{1}, E\right),\left(F_{2}, E\right),\left(F_{3}, E\right),\left(F_{4}, E\right)\right\}$

$\tau^{\prime}=\left\{\tilde{0}, \tilde{1},\left(G_{1}, E\right),\left(G_{2}, E\right)\right\}_{\text {be }}$ fuzzy soft topological spaces.

$X=\left\{h_{1}, h_{2}, h_{3}\right\} \quad Y=\left\{x_{1}, x_{2}, x_{3}\right\} \quad A=\left\{e_{1}, e_{2}\right\} \quad B=\left\{e_{1}^{\prime}, e_{2}^{\prime}\right\}$

$\left(F_{1}, E\right)=\{\{0.5,0.3,0.2\},\{0.3,0.5,0.2\}\}$

$\left(F_{2}, E\right)=\{\{1,0,0.5\},\{0.5,0.3,1\}\}$

$\left(F_{3}, E\right)=\{\{0.5,0,0.2\},\{0.3,0.3,0.2\}\}$

$\left(F_{4}, E\right)=\{\{1,0.3,0.5\},\{0.5,0.5,1\}\}$

$\left(G_{1}, E\right)=\{\{0.2,0.3,0.5\},\{0.2,0.5,0.3\}\}$

$\left(G_{2}, E\right)=\{\{0.8,0.7,0.5\},\{0.8,0.5,0.7\}\}$

Let us define the fuzzy soft mapping

$f_{p u}:(X, \tau) \rightarrow\left(Y, \tau^{\prime}\right)$

$$
\begin{aligned}
& \text { by } u\left(h_{1}\right)=x_{3}, u\left(h_{2}\right)=x_{2}, u\left(h_{3}\right)=x_{1} \\
& \text { and } p\left(e_{1}\right)=e_{1}^{\prime} p\left(e_{2}\right)=e_{2}^{\prime}
\end{aligned}
$$

Let $\mathrm{A}=\{\{0.1,0.2,0.5\},\{0.1,0.2,0.1\}\}$

Here $\mathrm{f}$ is fuzzy soft semi continuous but it is not fuzzy soft semi-g-continuous

\section{CONCLUSION}

In this paper we have introduced fuzzy soft Generalized closed set, $\mathrm{g}^{*}$-closed set and strongly $\mathrm{g}^{*}$-closed set and then studied some properties of these closed sets in Fuzzy soft topological spaces. Also we have introduced fuzzy soft gcontinuous function and fuzzy soft semi g-continuous function.

\section{REFERENCES}

[1] Zadeh L.A (1965) "Fuzzy sets", Information and Control, vol. 8, no. 3, pp. 338-353.

[2] Chang C.L(1968) "Fuzzy topological spaces", Journal of Mathematical Analysis and Applications, vol. 24, pp.182190.

[3] Kharal A and Ahmad B (2009) "Mappings on fuzzy soft classes", Advances in Fuzzy Systems, vol. 2009, Article ID 407890, 6 pages.

[4] Kandil A, Tanay O.A.E, El-Sheikh S.A and Abd Ellatif A.M (2014)“ Fuzzy semi open soft sets related properties in fuzzy soft topological spaces”, Journal of mathematics and computer science, 13:94-114.

[5] Varol B.P and Aygün .H (2012)“Fuzzy soft topology", Hacettepe Journal of Mathematics and Statistics, vol. 41, no. 3, pp. 407-419.

[6] N. Levine (2004), Semi-open sets and semicontinuity in topological spaces, Amer. Math. Monthly, J.K. Park and J.H. Park, Mildly generalized closed sets, almost normal and mildly normal Spaces, Chaos, Solitions and Fractals 20, 1103-1111.

[7] M.K.R.S. Veera Kumar(2000), between closed sets and g-closed sets, Mem. Fac. Sci. Kochi Univ. (Math.) 21, 1-19.

[8] R. Parimelazhagan and V. Subramoniapillai, Strongly $\mathrm{g}^{*}$-Closed sets in topological spaces, Int. Jou. Of Math. Anal. 6(30) (2012) 1481-1489.

[9] T.Rajendrakumar and G.Anandajothi "On Fuzzy Strongly g-Closed Sets in Fuzzy Topological Spaces" Intern. J. Fuzzy Mathematical Archive vol. 3, 2013, 68-75

[10] Maji P.K, Biswas R and Roy A.R (2001) "Fuzzy soft sets," Journal of Fuzzy Mathematics, vol.9 no. 3, pp. 589-602.

[11] Tanay. B and Kandemir M.B (2011) "Topological structure of fuzzy soft sets", Computers \& Mathematics with Applications, vol. 61, no. 10, pp. 2952-2957.

[12] Sabir hussain (2016) "On weak and strong forms of fuzzy soft open sets", Fuzzy Information and Engineering, vol 8, issue 4, pp 451-463. 